\title{
Control and Monitoring of $\mathrm{pH}$ process using Fuzzy Based Controller
}

\begin{abstract}
MANOJ V $\mathbf{~}^{1}$, VARUNKUMAR $S^{2}$, MANORANJITH $\mathbf{R}^{3}$, V.RADHIKA ${ }^{4}$
UG students, department of electronics and instrumentation, Sri Ramakrishna engineering college, coimbatore ${ }^{1,2,3}$ Assistant professor (sr.g), dept., of electronics and instrumentation, Sri Ramakrishna engineering college, coimbatore ${ }^{4}$

Abstract: In today scenario Industries use different types of process variables and parameters for measurement. Among that $\mathrm{pH}$ is the most important parameter. These $\mathrm{pH}$ measurements are prominent in the industries like food \& beverage, power plant, paper industries, paramedical industries etc. The smaller change in $\mathrm{pH}$ (amount of acid added, base solution and time) will lead to tedious effects in the process. The control of the $\mathrm{pH}$ process is also non-linear in nature and maintaining the $\mathrm{pH}$ value in the process is difficult for the desired transient response. In order to reduce problems fuzzy based system was designed and it is efficient than conventional integral controllers.
\end{abstract}

Keywords: Control of pH process, Fuzzy logic, MATLAB.

\section{INTRODUCTION}

Control of the $\mathrm{pH}$ neutralization process plays an $\mathrm{pH}=-\log [\mathrm{H}+]$

important role in different chemical plants, such as (1)The $\mathrm{pH}$ was defined earlier as the measure of the chemical and biological reaction, waste water treatment, acidity or the basic of a solution, and an acid was defined electrochemistry and precipitation plants, production of as the solution of $\mathrm{pH}$ less than 7 , and the base as that pharmaceuticals, fermentation, and food production such solution of $\mathrm{pH}$ larger than 7. More specifically, the $\mathrm{pH}$ was as in vegetable oil refining. The technology used within controlled in a continuously stirred tank reactor (CSTR) in the process industries has changed rapidly in recent years this experiment.The reaction being controlled was the as plant processes have become more and more complex. acid-base reaction of sodium hydroxide $(\mathrm{NaOH})$ and These changes are due to the increasing need for better hydrochloric acid (HCL). If the $\mathrm{pH}$ of the process solution product quality and requirements for the reduction of is maintained constantly by adding HCL to the CSTR is operating costs, including those associated with energy said to be acid control and if the $\mathrm{pH}$ of the process solution usage. Another important factor that contributes to the is maintained constantly by adding $\mathrm{NaOH}$ to the CSTR is development of process industry technology arises from said to be base control. Using process reaction curve the environmental legislation which not only puts significant open loop test is done and the transfer function is obtained demands on the process industries but is also constantly for both acid and base separately. Because transfer being revised. It is a known fact that a pH process plant is functions are need for stimulation of fuzzy controller using very difficult to model and control. It is often difficult to MATLAB.

achieve a high performance and robust $\mathrm{pH}$ control due to their time-varying and severe nonlinear characteristics. Hence $\mathrm{pH}$ control is often considered a bench mark for new models and control strategies. As a result, significant new constrains have emerged which reflect directly on plant process technology. Besides, sensors and actuators applied in industrial plants are devices which contribute with nonlinearities such as dead-zones, hysteresis and backlash. In order to overcome this issue, several linear control techniques have been used in nonlinear plants.

\section{OVERVIEW OF PROJECT}

As it is known, it has the characteristics of strong nonlinearity, multi constant, strong coupled time-varying and multi-input. The technology is complicated, which results in great difficulty in the course of modeling and optimization control. By manipulating control parameters, the $\mathrm{pH}$ level within the system can be kept within a certain range. To determine the proper control mechanism adaptive controlling schemes are used. The $\mathrm{pH}$ number is a measure of concentration or more precisely the activity $\mathrm{pH}$ of hydrogen ion in a solution.
The significance of $\mathrm{pH}$ control is to satisfy certain environmental requirements. This is mainly to protect life (aquatic and human) and also to prevent damage due to corrosion.

\section{Fluid takenfor $\mathrm{pH}$ process}

\section{PREPARATION OF SOLUTIONS}

HCL -0.1 molar concentration.

$\mathrm{NAOH}-0.1$ molar concentration.

Processsolution- Distilledwater.

Preparation of $1 \mathrm{pH}$ of acid

$\mathrm{pH} \quad=-\log [($ Amount of $\mathrm{HCl} / \mathrm{lit}) /$ Molecular Weight $]$

$=-\log [3.65 / 36.5]$

$=1$.

Preparation of $13 \mathrm{pH}$ of base

$\mathrm{pOH}=-\log [(\mathrm{Amount}$ of $\mathrm{NaOH} / \mathrm{lt}) / \mathrm{Molecular}$ Weight $]$

$\mathrm{pH} \quad=14-\mathrm{pOH}$

$=14-[-\log (4.0 / 40)]$

$=13$ 
NON LINEAR CHARACTERISTICS OF pH TITRATION CURVE

The acidity of the aqueous solution which is measured with a $\mathrm{pH}$ sensor plays a very important role in various physical, chemical and biological processes. For example, neutralization is required for biological treatment of wastewater stream.

The control of the $\mathrm{pH}$ level is known as a difficult problem due to its severe non-linearity shown in Fig.1. The nonlinearity of the $\mathrm{pH}$ process is represented with the titration curve and is usually considered as a gain variation.
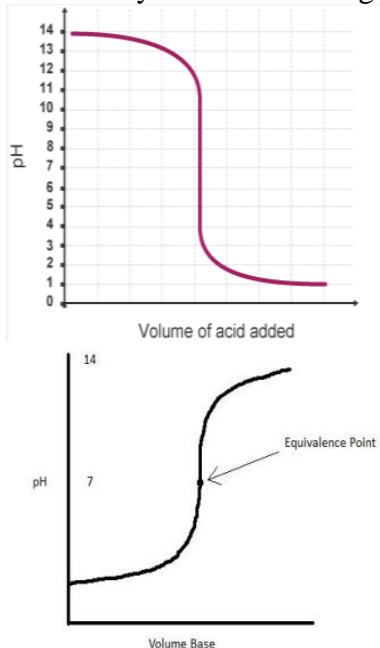

Fig.1.1 Titration curve for acid and base

The acidity measured in any solution plays very important role in any physical, chemical or biological process. Conventional controllers have poor performance or instability due to large gain variations in the controllers. This creates the necessity of a few controls that moderately controls the $\mathrm{pH}$ value.

\section{ANALYSE FOR pH VARIATION}

When experiments were done on taking some amount of HCL and distilled water shown in Table 3.1.

Table 3.1.Flow rate $(\mathrm{ml}) \mathrm{vs} \mathrm{pH}$ for acid

\begin{tabular}{|c|c|}
\hline ACID ADDED $(\mathrm{ml})$ & PROCESS FLUID $\mathrm{pH}$ \\
\hline 0 & 7 \\
\hline 0.3 & 3.4 \\
\hline 0.4 & 3 \\
\hline 0.5 & 2.8 \\
\hline 0.6 & 2.6 \\
\hline 0.7 & 2.5 \\
\hline 0.8 & 2.4 \\
\hline 0.9 & 2.2 \\
\hline 1 & 2.2 \\
\hline 1.1 & 2.1 \\
\hline 1.2 & 2.1 \\
\hline 1.3 & 2.1 \\
\hline 1.4 & 2.1 \\
\hline 1.5 & 2 \\
\hline 1.6 & 1.9 \\
\hline 1.7 & 1.9 \\
\hline 1.8 & 1.9 \\
\hline 1.9 & 1.9 \\
\hline 2 & 1.8 \\
\hline
\end{tabular}

It can be conclude that the $\mathrm{pH}$ process has nonlinear characteristics as inferred in Fig.3.1.

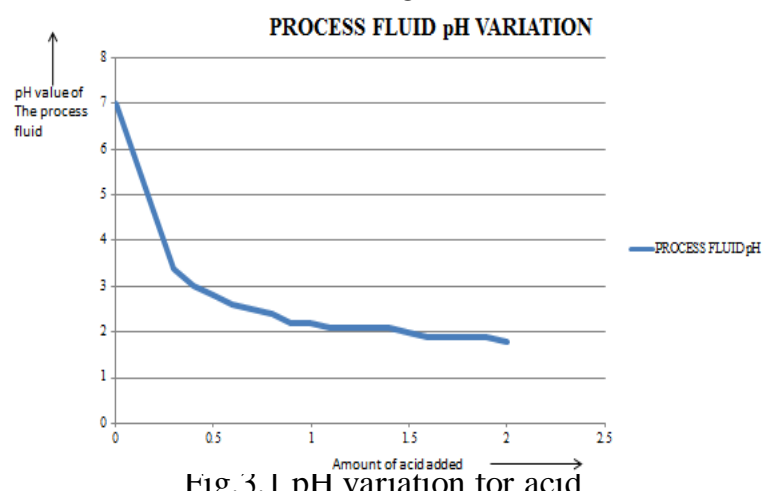

When experiments were done on taking some amount of $\mathrm{NaOH}$ and distilled water shown in Table 3.2.

Table 3.2Flow rate $(\mathrm{ml}) \mathrm{vs} \mathrm{pH}$ for base

\begin{tabular}{|c|c|}
\hline BASE ADDED (ml) & PROCESS FLUID pH \\
\hline 0 & 6.7 \\
\hline 0.1 & 8.4 \\
\hline 0.2 & 9.2 \\
\hline 0.3 & 9.4 \\
\hline 0.4 & 9.5 \\
\hline 0.5 & 9.7 \\
\hline 0.6 & 9.8 \\
\hline 0.7 & 9.9 \\
\hline 0.8 & 10 \\
\hline 0.9 & 10.1 \\
\hline 1 & 10.2 \\
\hline 1.1 & 10.2 \\
\hline 1.2 & 10.3 \\
\hline 1.3 & 10.3 \\
\hline 1.3 & 10.3 \\
\hline 1.4 & 10.3 \\
\hline 1.5 & 10.4 \\
\hline 1.6 & 10.4 \\
\hline
\end{tabular}

It can be conclude that the $\mathrm{pH}$ processes has nonlinear characteristics as referred in Fig.3.2

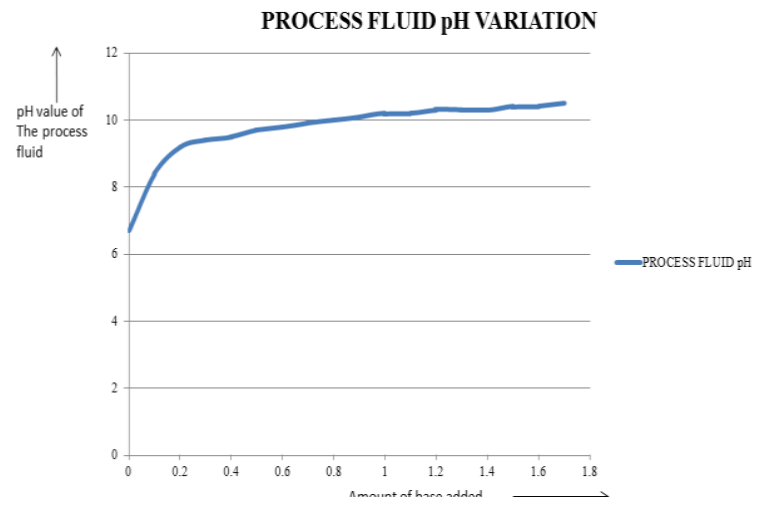

Fig.3.2pH variation for base 


\section{BLOCK DIAGRAM}

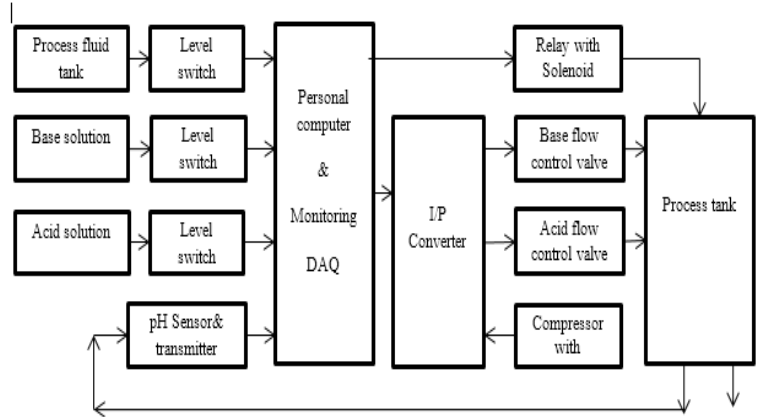

Fig.3.3Block diagram of $\mathrm{pH}$ process

\section{BLOCK DIAGRAM DESCRIPTION}

Solution tank

The setup consists of three solution tanks shown in Fig3.3. Each solution tank contains acid, base and water separately. Water is used only for neutralization purpose. The acid solution taken here is HCL $(0.1 \mathrm{M})$ and the base solution taken here is $\mathrm{NaOH}(0.1 \mathrm{M})$.Level switchEach solution has its own level switch shown in Fig., when the solution from the solution tank reduces below the level switch it indicated by an alarm.

$\mathrm{pH}$ sensor and transmitter

$\mathrm{pH}$ sensor is placed inside the process tank. It is used to measure the $\mathrm{pH}$ value of the process solution. The $\mathrm{pH}$ value is showed in the display present in the setup and the transmitter transmits the $\mathrm{pH}$ value in terms of current shown in Fig

Personal computer and DAQ (Data AcQuisition card)

DAQ will convert analog value into digital value as well as digital value into analog value. PC can accept only digital values so DAQ will convert analog value into digital value shown in Fig.3.1.The program is built in the $\mathrm{PC}$, where the percentage of valve opening can be given and the simulation graph is shown clearly. Once the valve opening is given the DAQ will convert the digital value into analog value. LabVIEW DAQ is used for this station. $\mathrm{I} / \mathrm{P}$ converter the current value is converted into pressure through I/P converter so that the control valve can move according to the percentage of valve open which is given in the PC shown in Fig.

Process tank

Process solution is present in the process tank, whose $\mathrm{pH}$ is to be maintained and controlled shown in Fig.3.1 Process tank has $\mathrm{pH}$ sensor and stirrer, which continuously stirs the solution. The flow of the acid and base solution is controlled by the control valve.

\section{PROCESS REACTION CURVE METHOD}

The process reaction curve methods works by generating a process reaction curve (below) in response to a disturbance. Controller gain, integral time and derivative time can be calculated using this curve shown in Fig.8. The process reaction curve is identified by performing in an open loop step test of the process and finding model parameters for initial step.

A typical process reaction curve is generated using the following method:
- $\quad$ Put the controller in manual mode.

- Wait until the process value reaches steady state or as close as possible (stable and not changing) Introduce a small disturbance - The step must be big enough to see a significant change in the process value. Collect data and plot

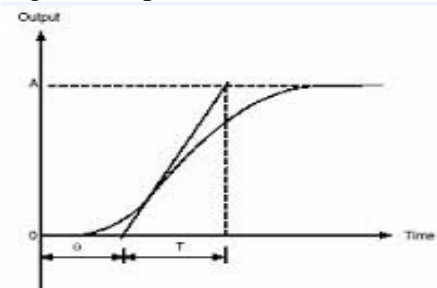

Fig.3.4 Process Reaction curve

Transfer function obtained using process reaction curve for base

Gain, $\quad \mathrm{K}=$ process output/process input $\mathrm{K}=0.04912$

Time delay $t_{d}=20 \mathrm{secs}$

Time constant $\tau=t-t_{d}$ $\tau=320$

The obtained transfer function is:

$$
\begin{aligned}
G p(s)=\frac{k \cdot e^{-t_{d} s}}{\tau_{s}+1} \\
G p(s)=\frac{0.04912 e^{-20 s}}{320 s+1}
\end{aligned}
$$

Transfer function obtained using process reaction curve for acid

Gain, $\mathrm{K}=$ process output/process input $\mathrm{K}=0.07114$

Time delay, $\quad t_{d}=20 \mathrm{secs}$

Time constant, $\tau=t-t_{d}$ $\tau=100$

The obtained transfer function is:

$$
\begin{aligned}
& G p(s)=\frac{k \cdot e^{-t_{d} s}}{\tau_{s}+1} \\
& G p(s)=\frac{0.07114 e^{-20 s}}{100 s+1}
\end{aligned}
$$

SIMULATION RESULTS

\section{MATLAB BLOCK DIAGRAM}

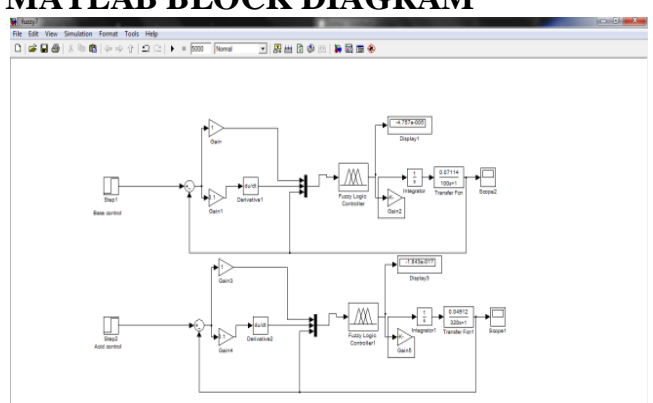

Fig.5.1MATLAB block diagram 


\section{RESPONSE FOR ACID CONTROL}

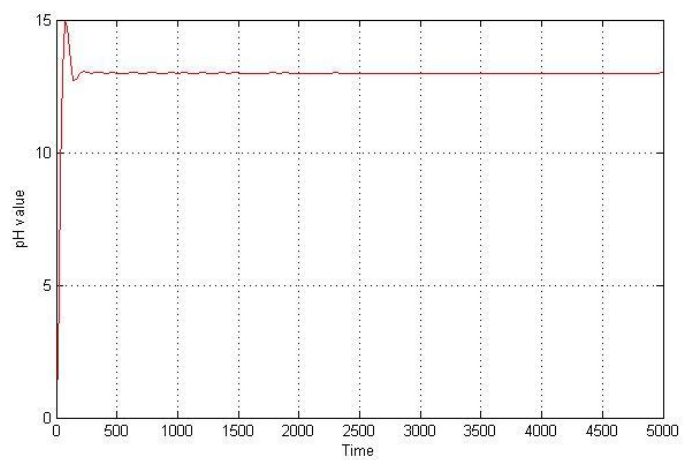

Fig.5.2MATLAB response for acid control RESPONSE FOR BASE CONTROL

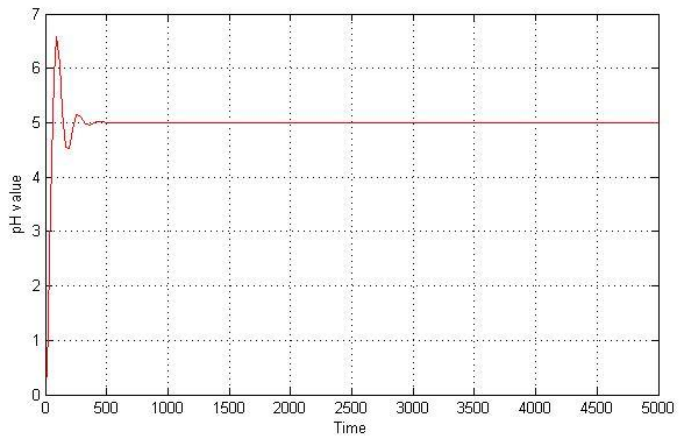

Fig.5.3MATLAB response for base control

\section{CONCLUSION}

This work is mainly aims on developing a fuzzy based control system for $\mathrm{pH}$ control and also to minimize the defects and the human negligence with the help of MATLAB. Unlike the other automated systems programmed using microcontrollers and PLC's, MATLAB serves the purpose of easy programming and has high flexibility.

\section{FUTURE SCOPE}

In the future, the work can be enhanced in many possible ways. Some of them are as follows:

The certain outside changes can be fed to the controller so it can also maintain the $\mathrm{pH}$ accurately.

More combination of MATLAB and embedded coding can be done to ensure that the system becomes fully automated and intelligent to the core

This work can be extended to design of neuro fuzzy logic controller which will be more effective.

\section{REFERENCES}

1. Alsabbah, Al-khedher, Abuzalata, Younes (2012), Evaluation of Multiregional Fuzzy Cascade Control For $\mathrm{pH}$ Neuterlization Process', International Journal of Research and Reviews in Applied Sciences (IJRRAS), Vol.10, No.2, pp.193-199.

2. D.F.Ahmed, S.K.H.Al-Dawery, H.A.O.Al-Anbari (2007), 'On-line Control of The Neutralization Process Based On Fuzzy Logic', Emirates Journal for Engineering Research (EJER), Vol.12, No.2, pp.89-97.

3. Hanamane, M.D. (2008), Implementation of Fuzzy logic control using microprocessor', Journal of Scientific and Industrial research(JSIR), Vol.65, No.3, pp-142-147 .

4. Mehdi zairisavzevar and Jamal ghobadidizajyekan (2013), 'Simulation of Temperature Controller for An Injection Mould Machine Using Fuzzy Logic', Journal of Mathematics and Computer Science (JMCS), Vol.7, No.1, pp.33-42.
5. Parikshitsihgh, Surekhabhanot, Hare krishnamohanta(2007), 'Optimizied And Self-organized Fuzzy Logic Contoller For pH Neutrlization Process', Emirates Journal for Engineering Research(EJER), Vol.12, No. 2, pp.99-112.

6. Dr.SantiPrabha, DurgaRao, SivaRamarishnan, (2011), 'Fuzzy Logic Based Intelligent Controller Design for An Injection Mould Machine Process Control', Journal of Instrument Society of India(JISOI), Vol.10, No.1, pp.98-103. 